\title{
Correction to: Dynamic linear models guide design and analysis of microbiota studies within artificial human guts
}

Justin D. Silverman ${ }^{1,2,3}$, Heather K. Durand ${ }^{5}$, Rachael J. Bloom ${ }^{4}$, Sayan Mukherjee ${ }^{1,6}$ and Lawrence A. David ${ }^{1,3,4,5^{*}}$

\section{Correction}

Following publication of the original article [1], the authors noticed an error in the presentation of equations in the PDF version.

On page 10:

Equation 3 reads as:

$$
\eta_{k}=F_{k}^{\theta^{\prime}{ }_{k}+v_{k},}, v_{k} \sim N\left(0, V_{k}\right)
$$

but should read as:

$$
\eta_{k}=F_{k}^{\prime} \theta_{k}+v_{k}, v_{k} \sim N\left(0, V_{k}\right)
$$

On page 12:

The equation reads as:

$$
\eta_{k}=\left[I_{R} \otimes F_{k}^{\prime} \theta_{k}+v_{k}, \quad v_{k} \sim N\left(0,\left[I_{R} \otimes V_{k}\right]\right)\right.
$$

but should read as:

$$
\eta_{k}=\left[I_{R} \otimes F_{k}^{\prime}\right] \theta_{k}+v_{k}, \quad v_{k} \sim N\left(0,\left[I_{R} \otimes V_{k}\right]\right)
$$

The original article has been updated.

\section{Author details}

'Program in Computational Biology and Bioinformatics, Duke University, CIEMAS, Room 2171, 101 Science Drive, Box 3382, Durham, NC 27708, USA. ${ }^{2}$ Medical Scientist Training Program, Duke University, Durham, NC 27708, USA. ${ }^{3}$ Center for Genomic and Computational Biology, Duke University, Durham, NC 27708, USA. ${ }^{4}$ University Program in Genetics and Genomics, Duke University, Durham, NC 27708, USA. ${ }^{5}$ Department of Molecular Genetics and Microbiology, Duke University, Durham, NC 27708, USA. ${ }^{6}$ Departments of Statistical Science, Mathematics, Computer Science, Biostatistics \& Bioinformatics, Duke University, Durham, NC 27708, USA.

* Correspondence: lawrence.david@duke.edu

'Program in Computational Biology and Bioinformatics, Duke University, CIEMAS, Room 2171, 101 Science Drive, Box 3382, Durham, NC 27708, USA ${ }^{3}$ Center for Genomic and Computational Biology, Duke University, Durham, NC 27708, USA

Full list of author information is available at the end of the article
Published online: 27 November 2018

\section{Reference}

1. Silverman JD, Durand HK, Bloom RJ, Mukherjee S, David LA. Dynamic linear models guide design and analysis of microbiota studies within artificial human guts. Microbiome. 2018;6:202.

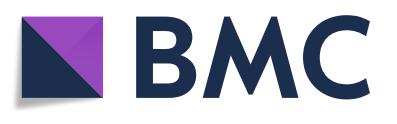

(c) The Author(s). 2018 Open Access This article is distributed under the terms of the Creative Commons Attribution 4.0 International License (http://creativecommons.org/licenses/by/4.0/), which permits unrestricted use, distribution, and reproduction in any medium, provided you give appropriate credit to the original author(s) and the source, provide a link to the Creative Commons license, and indicate if changes were made. The Creative Commons Public Domain Dedication waiver (http://creativecommons.org/publicdomain/zero/1.0/) applies to the data made available in this article, unless otherwise stated. 